\title{
Analysis of Stress and Deflection about Steel-Concrete Composite Girders Considering Slippage and Shrink \& Creep Under Bending
}

\author{
Cheng Haigen ${ }^{*}$
}

\author{
School of Civil Engineering, East China Jiaotong University, Nanchang, JiangXi, 330013, P.R. China
}

\begin{abstract}
Steel-concrete composite beams are composed of concrete slabs and steel girders by shear connectors. Due to the limited rigidity of shear connector, and the shrink \& creep property of concrete, relative slippage exists between the concrete slab and steel girder under bending, and it is difficult to analyze the effect of those factors by the ordinary beam theory, the finite element method(FEM) and so on. A differential equation of equilibrium is constituted corresponding to the compatibility of deformation and the equilibrium of forces of steel-concrete composite beams under particular assumed condition. Finite difference method (FDM) and variation principle are used to solve the differential equation. An example of steel-concrete composite $\mathrm{T}$ girder is given to analyze the effect of slippage and concrete shrink \& creep on its stress and deflection. The concrete slab stress increases with increased rigidity in the shear connectors. The stress of the steel girder and the deflection of the composite girder decrease with increment in the rigidity of the shear connectors.
\end{abstract}

Keywords: Differential equations, relative slippage, steel-concrete composite beams, shrink \& creep, variation principle.

\section{INTRODUCTION}

Composite beams are usually composed of concrete slab, which bears compressive stress and the steel beam, which bears the tensile stress. This combination takes full advantage of tensile capacity of steels and compression capacity of concretes, respectively. For this kind of beam, there is a larger difference between the stress calculated by the primary beam theory and the actual stress. The discrepancy is observed not only in the distribution of stress along the transverse section, but also in the relationship between stress and time. In order to solve this problem, many scholars have conducted some researches and put forward some feasible calculation theories and methods, such as energy-variational method, the finite plate strip method, the finite element method, and so on [1-3]. Some researchers have performed corresponding model experimental research [4-7]. Kristek solved the problem by using the method of series [8], independent of the condition of relative slip. However, the fact is that the steel beam and concrete plate of steel - concrete composite beam were combined together by shear connectors [2]. Because the stiffness of connecting bond is limited, there is a relative slip tendency between steel beam and concrete slab. Moreover, because concrete has the property of shrinkage and creep, it is necessary to consider the influence of the property and relative slip of concrete. According to the principle of deformation compatibility and equilibrium conditions, this paper deduced the equilibrium differential equation of composite beam under the condition of considering the relative slippage, and verified the reliability and the accuracy of the approximate method by giving examples.

*Address correspondence to this author at the School of Civil Engineering, East China Jiaotong University, Nanchang, Jiangxi, 330013, P.R. China; Tel: 13879104029; E-mail: bridge407@126.com

\section{DIFFERENTIAL EQUATION OF THE COORDI- NATION OF BALANCE AND DEFORMATION}

\subsection{The Basic Assumptions}

The steel -concrete composite girders are shown in Fig. (1). Several assumptions are as follows [9, 10]:

(1) There is no vertical detachment between concrete slab and steel in the composite girder under bending. That is, both of them have the same vertical displacement.

(2) The displacement does not take place at any cross section in $\mathrm{x}$ direction (As shown in Fig. 1). Namely, lateral bending is not observed.

(3) The maximum shear angle's difference function of concrete slab and flange plate of steel beam is $f(z, t)$. While the distribution function of shear angle on transverse section is $\psi(\mathrm{x})$.

(4) The shear connectors are mainly distributed in the junction of flange plate and Web, and the relative slip between the concrete slab and steel beam are mainly concentrated. Moreover, slip will be linear with respect to the shear force of shear connectors.

(5) The normal strain $\varepsilon z$ and shearing strain $\gamma \mathrm{xz}$ of concrete slab are considered in the longitudinal direction ( $\mathrm{z}$ direction), ignoring the strain out of plane and transverse; [10] Fig. (6). In addition, the normal strain $\varepsilon z$ of steel beam is considered in the longitudinal direction, while the other strain is ignored.

(6) Shear force is linear with respect to the strain on the steel beam. The linear elastic constitutive relations for shear force and strain of concrete are satisfied. 


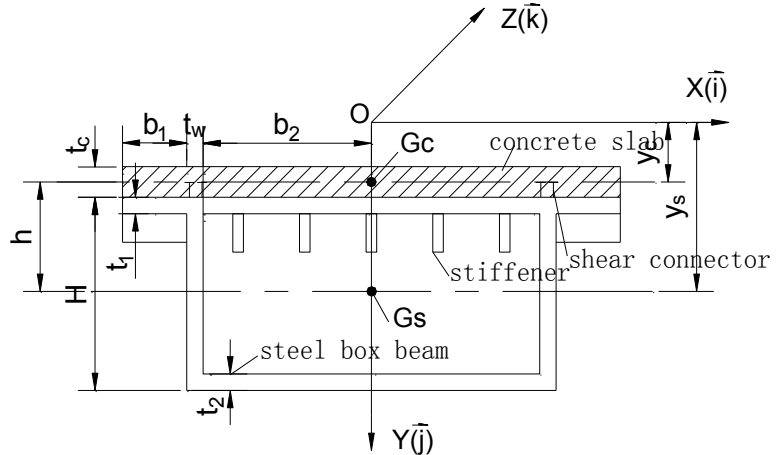

a) Composite box girder

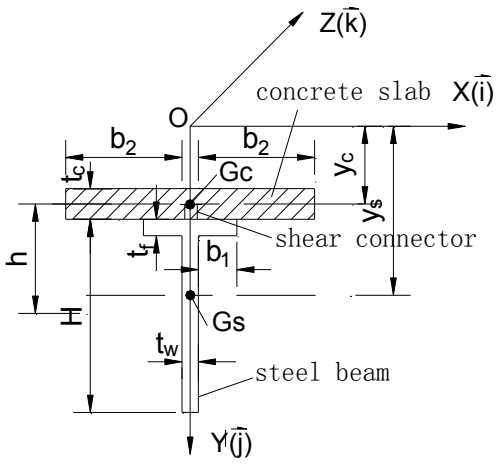

b) Composite T-girder

Fig. (1). Cross section of typical composite girder.

\subsection{Establishing the Differential Equation and Solutions}

When the load is applied on the beam, the deformation of cross section is shown in Fig. (2). The displacement component of concrete slab and steel beam on $\mathrm{Z}$ direction (longitudinal direction) is $\mathrm{wc}(\mathrm{z}, \mathrm{t})$ and $\mathrm{ws}(\mathrm{z}, \mathrm{t})$, respectively. The displacement components of both of them on $y$ direction (vertical direction) is $v(z, t)$. Subsequently, the displacement vector form of an arbitrary point on concrete slab and steel beam can be expressed as follows:

$$
\vec{u}_{c}(x, y, z, t)=v(z, t) \vec{j}+\left[w_{c}(z, t)-\left(y-y_{c}\right) v^{\prime}(z, t)+f(z, t) \psi(x)\right] \vec{k}
$$

Steel beam

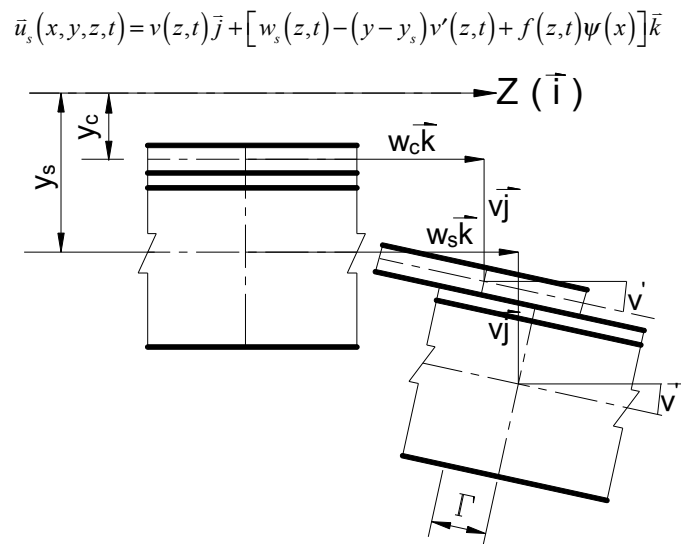

Fig. (2). Deformation diagrams of composite girder Concrete slab.

Where, $z$ means the distance in $z$ direction from an arbitrary point to the origin of coordinates; $y$ means the distance in $x$ direction from an arbitrary point to the origin of coordinates; $y_{c}$ and $y_{s}$ respectively represent the distance from the part of concrete-steel beam's centroid axis to the reference axis. $j$, and $k$ are unit vectors in the reference coordinates $y$ and $z$ axis,respectively.

According to the assumption of (3) and (4), the lateral distribution function $\psi(x)$ of the maximum difference $f(z, t)$ of the shear angle will satisfy the following conditions:

(1) At the midpoint and the side of flange plate, the first derivative is zero, which ensures that the shear stress is also zero;
(2) In the junction of flange slab and Web, $\psi(x)=0$. This condition simplifies the relative slip function between concrete slab and steel beam.

According to the above conditions, the relative slip function between concrete slab and steel beam can be obtained by formulas (1) and (2).

$\Gamma(z, t)=w_{s}(z, t)-w_{c}(z, t)+v^{\prime}(z, t) h$

Where, $\mathrm{h}$ represents the distance between the concrete slab and steel beam. Centroid axis because of the relative slippage and the linear relationship of interaction between contact surfaces based on constitutive relation of shear connectors can be obtained as follows:

$q_{z}(z, t)=R_{s} \Gamma(z, t)=R\left(w_{s}-w_{c}+v^{\prime} h\right)$

Where, $R_{\mathrm{S}}$ is the stiffness of shear connectors $\left(\mathrm{kN} / \mathrm{mm}^{2}\right)$.

According to formulas (1) and (2), the strain and stress of an arbitrary point on concrete slab and steel beam respectively are:

Concrete slab

$$
\begin{aligned}
& \left.\begin{array}{l}
\varepsilon_{z}(x, y, z, t)=w_{c}^{\prime}-\left(y-y_{c}\right) v^{\prime \prime}+f^{\prime} \psi \\
\gamma_{x z}(x, y, z, t)=f \psi^{\prime}
\end{array}\right\} \\
& \sigma_{z}=E_{c} \varepsilon_{z}=E_{c} w_{c}^{\prime}-E_{c}\left(y-y_{c}\right) v^{\prime \prime}+E_{c} f^{\prime} \psi \\
& \tau_{z x}=G \gamma_{x z}=G f \psi^{\prime}
\end{aligned}
$$

Steel beam

$$
\begin{aligned}
& \varepsilon_{z}(x, y, z ; t)=w_{s}^{\prime}-\left(y-y_{s}\right) v^{\prime \prime}+f^{\prime} \psi \\
& \sigma_{z}(x, y, z ; t)=E_{s} \varepsilon_{z}=E_{s} w_{s}^{\prime}-E_{s}\left(y-y_{s}\right) v^{\prime \prime}+E_{s} f^{\prime} \psi
\end{aligned}
$$

Where, $E_{\mathrm{s}}$ is the elastic modulus of steel; $E_{\mathrm{c}}$ is the elastic modulus of concrete; and $G$ is the shear modulus of concrete.

It was assumed that the composite beam wasin a state of balance under the body load $B(\mathrm{z}, t)$ and the surface load $\mathrm{s}$ $(z, t)$. Assuming that the longitudinal displacement (wc,ws), the vertical displacement $(v)$ and the maximum difference of shear and angle $f(z, t)$, all of them experienced a slight 
change $(\delta \mathrm{v}, \delta \mathrm{wc}, \delta \mathrm{ws}, \delta \mathrm{f})$. According to the principle of virtual work, virtual work done by the external force at constant distance equal to that done by micro section stress resulted in deformation, that is:

$$
\begin{aligned}
& \int_{0}^{L}\left[N_{c} \delta w_{c}^{\prime}+N_{s} \delta w_{s}^{\prime}-\left(M_{c}+M_{s}\right) \delta v^{\prime \prime}+\mu_{c} \delta f^{\prime}+\eta_{c} \delta f+\right. \\
& \left.q_{z}\left(\delta w_{s}-\delta w_{c}+h \delta v^{\prime}\right)\right] d z=\int_{0}^{L}\left(p_{y} \delta v+\right. \\
& \left.p_{c z} \delta w_{c}+p_{s z} \delta w_{s}-m \delta v^{\prime}+b \delta f\right) d z+ \\
& {\left[\bar{T} \delta v+\bar{N}_{c} \delta w_{c}+\bar{N} \delta w_{s}-\bar{M} \delta v^{\prime}+\bar{\mu} \delta f\right]_{0}^{L}}
\end{aligned}
$$

Where, $N_{\mathrm{c}}$, and $N_{\mathrm{s}}$ represent the axial force which is synthesized by the section stress of concrete slab and steel beam, respectively; $M_{\mathrm{c}}$, and $\mathrm{Ms}$ represent bending moment synthesized by the section stress of concrete slab and steel beam,respectively; $\mu_{\mathrm{c}}$, and $\eta c$ represent double bending moment and double shear force, respectively, synthesized by the section stress of concrete slab; $P_{\mathrm{y}}$ is the force resolved by resultant of forces in y direction; $P_{\mathrm{CZ}}$, and $P_{\mathrm{SZ}}$ represent the forces resolved by resultant of forces on concrete slab and steel beam in $\mathrm{z}$ direction, respectively; $\mathrm{M}$ is the total bending moment caused by the force exerted on each corresponding centroid axis, and the force is resolved by the load on concrete slab and steel beam in $z$ direction; $b$ is the load resolved broadly in $\mathrm{z}$ direction under the condition of considering the shear lag effect of concrete slab; $\bar{T}$ is the resultant of forces synthesized by the surface load in $\mathrm{y}$ direction; $\bar{N}_{c}$, and $\bar{N}_{s}$ are the resultant forces synthesized by the surface load on steel beam and at the end of the section of concrete slab, respectively, resolved in z direction; $\bar{M}$, and $\bar{\mu}$ are the bending moment and double bimoment, respectively, synthesized by load at the end of the section, and the load is resolved by surface load in $\mathrm{z}$ direction. Each resultant of forces is given as :

Resultant of forces on section stress

$$
\begin{aligned}
& N_{s}(z, t)=\iint_{A_{s}} \sigma_{z} d a=E_{s} A_{s} w_{s}^{\prime}+E_{s} S_{\psi} f^{\prime} ; \\
& M_{s}(z, t)=\iint_{A_{s}} \sigma_{z}\left(y-y_{s}\right) d a=-E_{s} I_{s} v^{\prime \prime} \\
& N_{c}(z, t)=\iint_{A_{c}} \sigma_{z} d a=E_{c}\left[A_{c}\left(w_{c}^{\prime}-\varepsilon_{s h}\right)+S_{\psi} f^{\prime}\right] ; \\
& M_{c}(z, t)=\iint_{A_{c}} \sigma_{z}\left(y-y_{c}\right) d a=-E_{c} I_{c} v^{\prime} ; \\
& \mu_{c}(z, t)=\iint_{A_{c}} \sigma_{z} \psi d a=E_{c}\left[\left(w_{c}^{\prime}-\varepsilon_{s h}\right)+I_{\psi} f^{\prime}\right] ; \\
& \eta_{c}(z, t)=\iint_{A_{c}} \tau_{x z} \psi^{\prime} d a=G I_{d \psi} f
\end{aligned}
$$

Resultant of forces on imposed load

$$
\begin{aligned}
& p_{y}(z, t)=\iint_{A_{c}} b_{y} d a+\int_{\partial A_{c}} s_{y} d l+\iint_{A_{s}} b_{y} d a+\int_{\partial A_{s}} s_{y} d l ; \\
& p_{c z}(z, t)=\iint_{A_{c}} b_{z} d a+\int_{\partial A_{c}} s_{z} d l ; \\
& m(z, t)=\iint_{A_{c}} b_{z}\left(y-y_{c}\right) d a+\int_{\partial A_{c}} s_{z}\left(y-y_{c}\right) d l+\iint_{A_{s}} b_{z}\left(y-y_{s}\right) d a+\iint_{\partial A_{s}} s_{z}\left(y-y_{s}\right) d l \\
& p_{s z}(z, t)=\iint_{A_{s}} b_{z} d a+\int_{\partial A_{s}} s_{z} d l ; b(z, t)=\iint_{A_{c}} b_{z} \psi d a+\int_{\partial A_{c}} s_{z} \psi d l
\end{aligned}
$$

Resultant of forces at the end section surface

$$
\begin{aligned}
& \bar{T}=\iint_{A_{c}} s_{y} d a+\iint_{A_{s}} s_{y} d a ; \\
& \bar{N}_{c}=\iint_{A_{c}} s_{z} d a ; \bar{N}_{s}=\iint_{A_{s}} s_{z} d a ; \\
& \bar{M}=\iint_{A_{c}} s_{z}\left(y-y_{c}\right) d a+\iint_{A_{s}} s_{z}\left(y-y_{s}\right) d a ; \bar{\mu}=\iint_{A_{c}} s_{z} \psi d a
\end{aligned}
$$

Where, $A_{c}$, and $I_{c}$ are the area of concrete slab and the moment of inertia on the centroid axis of the cross section, respectively; $A_{s}$, and $I_{s}$ are the area of steel beam and the moment of inertia on the centroid axis of the cross section, respectively.

$S_{\psi}=\iint_{A_{c}} \psi d a, \quad I_{\psi}=\iint_{A_{c}} \psi^{2} d a, \quad I_{d \psi}=\iint_{A_{c}} \psi^{\prime 2} d a$.

Putting the above formulas into formula (9), by employing the theory of subsection integral, the equilibrium differential equation and corresponding boundary conditions can be obtained as follows:

$$
\left.\begin{array}{l}
-E_{c}\left[A_{c}\left(w_{c}^{\prime \prime}-\varepsilon_{s h}^{\prime}\right)+S_{\psi} f^{\prime \prime}\right]-R_{s}\left(w_{s}-w_{c}+v^{\prime} h\right)=p_{c z} \\
-E_{s} A_{s} w_{s}^{\prime \prime}-S_{\psi} f^{\prime \prime}+R_{s}\left(w_{s}-w_{c}+v^{\prime} h\right)=p_{s z} \\
\left(E_{c} I_{c}+E_{s} I_{s}\right) v^{\prime \prime \prime \prime}-h R_{s}\left(w_{s}^{\prime}-w_{c}^{\prime}+v^{\prime \prime} h\right)=p_{y}+m^{\prime} \\
-E_{c} S_{\psi}\left(w_{c}^{\prime \prime \prime}-\varepsilon_{s h}^{\prime}\right)-E_{c} I_{\psi} f^{\prime \prime \prime}+\frac{E_{c 0} I_{d \psi}}{2(1+v)} f=b
\end{array}\right\}
$$

Boundary conditions

$$
\begin{aligned}
& {\left.\left[E_{c} A_{c}\left(w_{c}^{\prime}-\varepsilon_{s h}\right)+E_{c} S_{\psi} f^{\prime}-\bar{N}_{c}\right] \delta w_{c}\right|_{0} ^{L}=0} \\
& {\left.\left[E_{s} A_{s} w_{s}^{\prime}+S_{\psi} f^{\prime}-\bar{N}_{s}\right] \delta w_{s}\right|_{0} ^{L}=0} \\
& {\left.\left[-\left(E_{c} I_{c}+E_{s} I_{s}\right) v^{\prime \prime}-\bar{M}\right] \delta v^{\prime}\right|_{0} ^{L}=0} \\
& {\left.\left[-\left(E_{c} I_{c}+E_{s} I_{s}\right) v^{\prime \prime \prime}+h R_{s}\left(w_{s}-w_{c}+v^{\prime} h\right)-\bar{T}+m\right] \delta v\right|_{0} ^{L}=0} \\
& {\left.\left[E_{c} S_{\psi}\left(w_{c}^{\prime}-\varepsilon_{s h}\right)+E_{c} I_{\psi} f^{\prime}-\bar{\mu}\right] \delta f\right|_{0} ^{L}=0}
\end{aligned}
$$

It is very difficult to obtain the analytical expression of formula (10). Therefore numerical solution is usually used to solve this problem. Among the numerical methods, the difference method is highly accurate. This paper will not introduce the difference method. Readers can refer to the relevant content in the reference [11]. 


\section{EXAMPLE}

As shown in Fig. (3), each end of the beam is consolidated, using the corresponding model of the shrinkage and creep of concrete in specification [12]. Assuming that in the negative moment zone, the beam has prestressed reinforcement, therefore, the tensile stress does not appear in the tension zone of concrete beam - The strength of concrete is $f_{\mathrm{ck}}=35 \mathrm{MPa}$, Poisson ratio is $v=0.15$, the elastic modulus of steel is $E=2.1 \times 105 \mathrm{MPa}$, relative humidity in the environment is $75 \%$ and $50 \%$, even load is $64.1 \mathrm{kN} / \mathrm{m}$, and the stiffness of shear connectors is $0.6 \mathrm{kN} / \mathrm{mm} 2$ and $6 \mathrm{kN} / \mathrm{mm}^{2}$.

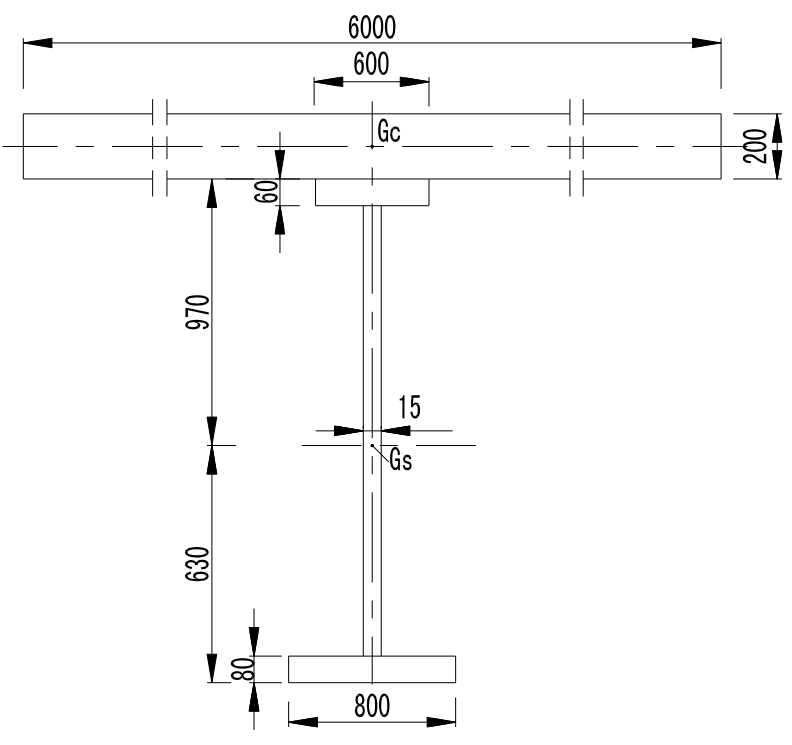

a) Cross section

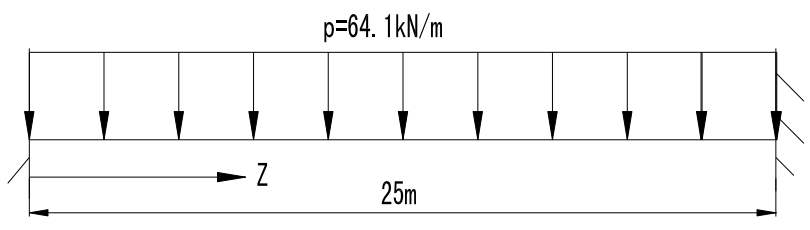

b) Structural sketch

Fig. (3). A typical sample.

As shown in Fig. (4), it is the influence of shear lag effect that causes deflection in the composite beam. If shear lag effect is considered, the results of theoretical calculation will show larger deflection. With the passage of time, the deflection of composite beam is increased accordingly. Shear lag effect also has a certain influence on the deflection of composite beam. Moreover, with increase in the stiffness of shear connectors, the degree of influence also gradually increases.

Fig. (4) and Fig. (5) show the influence of the stiffness of shear connector and relative environmental humidity on composite beam. With increase in the stiffness of shear connector, the beam's deflection reduced accordingly. With the development of concrete shrinkage and creep, beam's deflection increased, but the increase had a relation with the stiffness of the shear connectors. If the stiffness of shear connectors is larger, the magnitude of change of deflection is larger. As shown in Fig. (6), the effect of environmental humidity on the deflection of composite beam is not too obvious. If the stiffness of shear connector is larger, the influence of environmental humidity on the deflection of composite beam will also be larger.

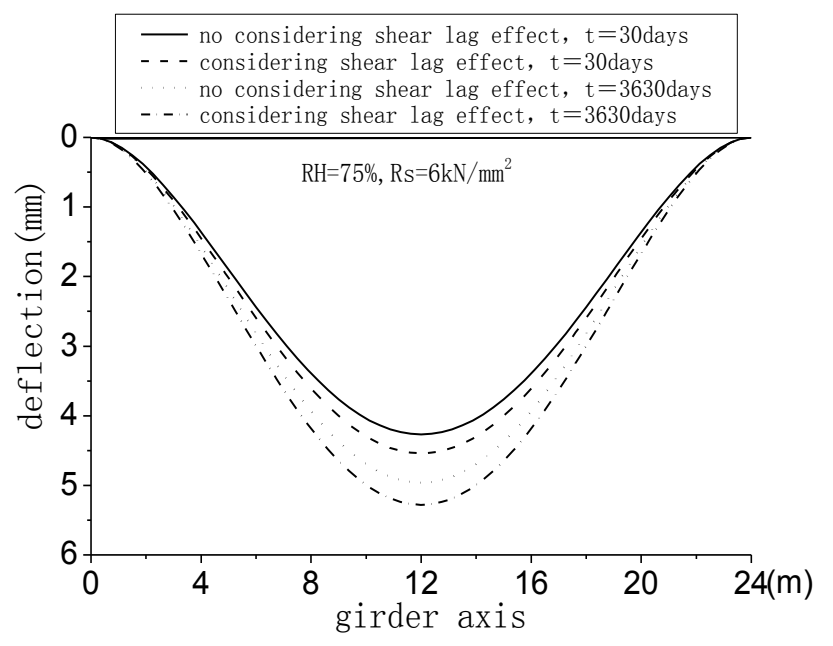

a) Beam deflection at $\mathrm{Rs}=0.6 \mathrm{kN} / \mathrm{mm}^{2}$

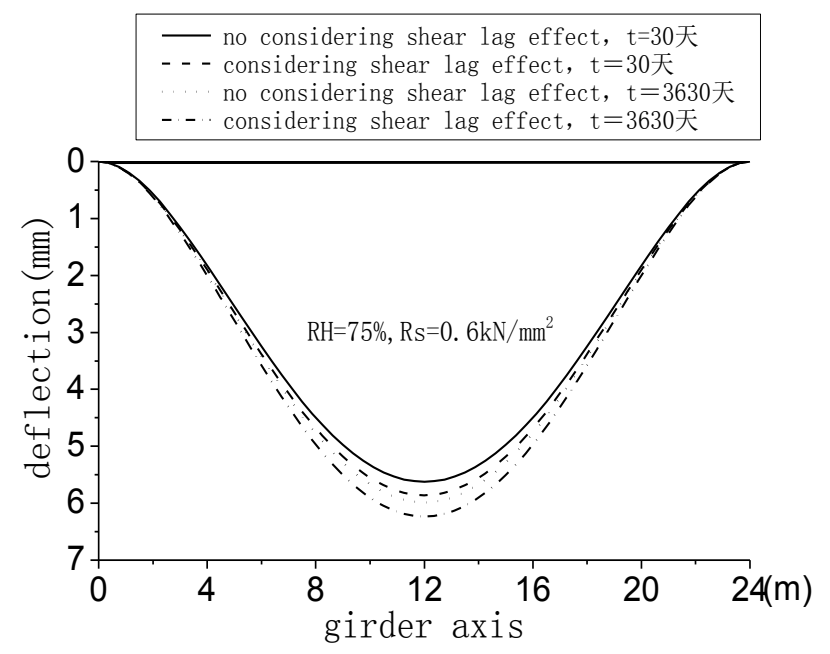

b) Beam deflection at $\mathrm{Rs}=6 \mathrm{kN} / \mathrm{mm}^{2}$

Fig. (4). Effect on deflection about shear lag.

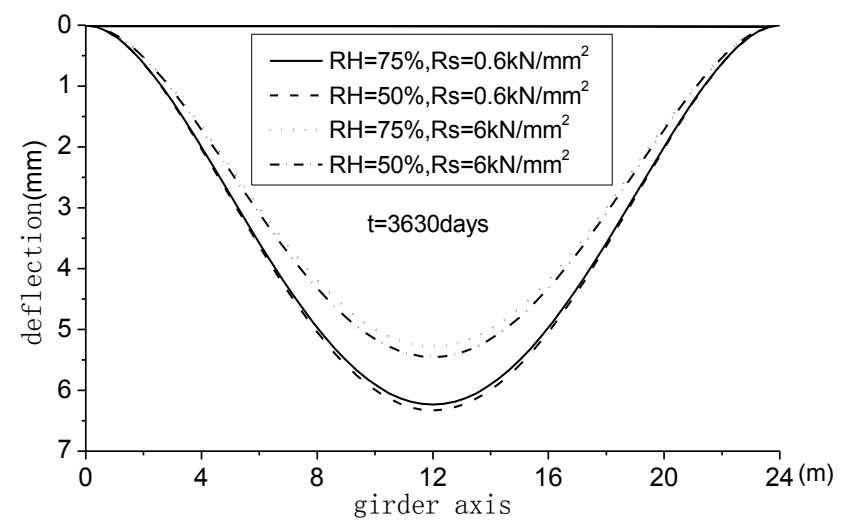

Fig. (5). Effect on deflection about the rigidity of shear connectors. 
As shown in Fig. (7) and Fig. (8), with the manifestation of shrinkage and creep of concrete, the sectional internal force isredistributed and the stress of the concrete slab varies with time. When load is applied on concrete slab initially, the stress changes much quickly. This can rapidly improve the shrinkage and creep of concrete earlier, while after eight months, the stress of the concrete slab changes very slowly. Because of the existence of shear connectors in composite beam, it will have an effect on the redistribution of sectional internal force after the beam applies load. Increased stiffness in the shear connector will benefit the distribution of cross-sectional stress .

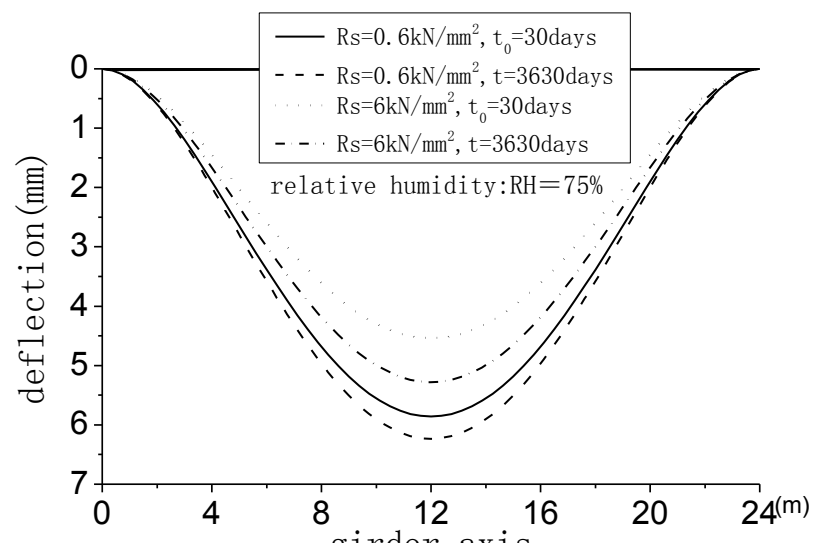

Fig. (6). Effect on deflection about RH of surrounding.

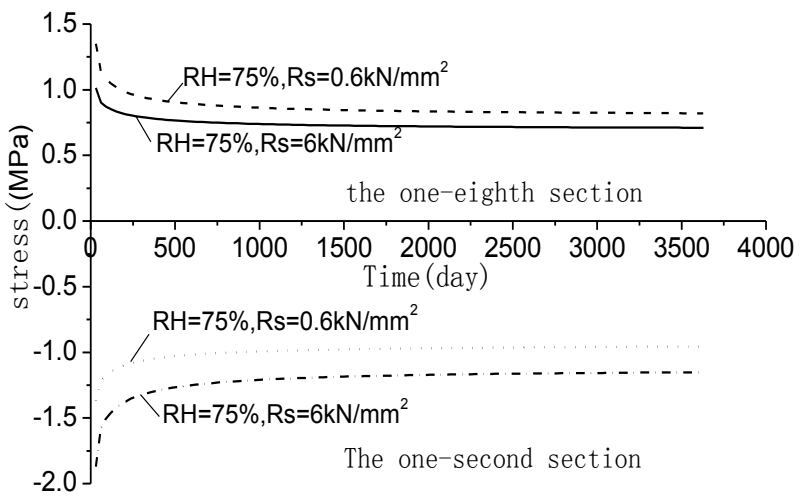

Fig. (7). Stress course of concrete slab.

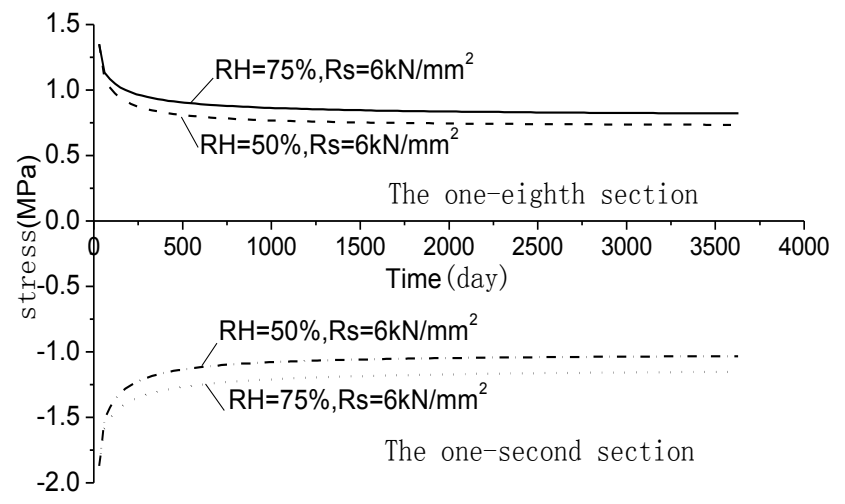

Fig. (8). The relationship between concrete stress and RH of surrounding.

\section{CONCLUSION}

According to the above results of the sample, the following conclusions are drawn:

1. If the lateral uneven distribution of sectional stress on composite beams is considered, the value of deflection will be larger than thatcalculated by ordinary beam theory, and the deflection of composite beam will be increased accordingly over time. But with increase in the stiffness of shear connectors, its influence degree will gradually increase.

2. The deflection of composite beam will decrease with increase in the stiffness of shear connector, and it will increase with the manifestation of creep and shrinkage in the concrete. But the increase corresponds to the stiffness of the shear connectors. If the stiffness of shear connectors is substantial, the magnitude of the change of deflection will be larger.

3. When the relative environmental humidity is high, the corresponding stress will change slowly, because of slow development of shrinkage and creep of concrete .

In summary, when the composite is bended, the main influence factor about stress and deflection is the stiffness of the shear connectors. The increase in the stiffness of shear connectors bond will have advantages in decreasing the deflection of beam. The change in the humidity of the environment will have little effect on the final value of stress and deflection.

\section{CONFLICT OF INTEREST}

The authors confirm that this article content has no conflict of interest.

\section{ACKNOWLEDGEMENTS}

The authors wish to acknowledge the support and motivation provided by the National Natural Science Foundation of China (Grant No. 51068005).

\section{REFERENCES}

[1] K.M. Sennah, X. Zhang, and J.B. Kennedy, "Impact factors for horizontally curved composite box girder bridges," Journal of Bridge Engineering, vol. 9, no. 6, pp. 512-520, Jun. 2004.

[2] J. Liu, Z. Zhang, and W. Li, "Finite element anaiysis of concretesteel beam," Journal of Shandong Jiaotong University, vol. 17, no. 1, pp. 36-39, Jan. 2009.

[3] S. Zhou, "A finite beam element considering shear lag effect in box girder," Journal of Engineering Mechanics, vol.26 pp. 42-50, Feb. 2010.

[4] G. Sun, R. Guan, Y. Jiang, C. Mu, C. Huo, and F. Xu, "Sunshineinduced temperature distribution on cross section of steel-concrete composite beams," Engineering Mechanics, vol. 23, no. 11, pp. 122-127, Nov. 2006.

[5] Y. Jiang, S. Xu, and L. Huang, "Nonlinear FEM analysis of steel fiber reinforced concrete composite beam and the computer simulation of the entire failing process," Journal of Sichuan University (Engineering Sciences), vol. 42, no. 1, pp. 80-86, Jan. 2010.

[6] Y. Yang, and W. Xue, "Experinental study on the static behavior of reinforced concrete composite T-beams," China Civil Engineering Journal, vol. 43, no. 3, pp. 1-7, March, 2010.

[7] T. Hu, C. Huang, X. Chen, and Z. Liang, "Experinental study on the fatigue property of composite beams with steel fiber reinforced 
self-stressing concrete in the negative moment area," China Civil Engineering Journal, vol. 42, no. 11, pp. 23-30, Nov. 2009.

[8] V. Kristek, "A shear lag analysis for composite box girder," Journal of Construction Steel Research, vol. 16, no. 1, pp. 15-17, Jan. 1990.

[9] L. Dezi, F. Gara, G. Leoni, and A.M. Tarantino, "Time-Dependent analysis of shear lag effect in composite beams," Journal of Engineering Mechanics, vol. 127, no. 1, pp. 71-79, Jan. 2001.
[10] Y. Long, and S. Bao, "Structural Mechanics", P.R.China, Beijing, 1986, pp. 123-130

[11] L. Wang, and J. Li, "Structural Analysis of the Finite-difference Method," P. R. China, Beijing, 1986, pp. 64-80.

[12] A.-M. Tarantino and L. Dezi, "Creep effects in composite beams with flexible shear connector," Journal of Structural Engineering, vol. 118, no. 1, pp. 2063-2081, Jan. 1992.

(C) Cheng Haigen; Licensee Bentham Open

This is an open access article licensed under the terms of the Creative Commons Attribution Non-Commercial License (http://creativecommons.org/licenses/ by-nc/4.0/) which permits unrestricted, non-commercial use, distribution and reproduction in any medium, provided the work is properly cited. 